Review began 09/23/2021 Review ended 09/24/2021 Published 09/28/2021

๑) Copyright 2021

Bara et al. This is an open access article distributed under the terms of the Creative Commons Attribution License CC-BY 4.0. which permits unrestricted use, distribution, and reproduction in any medium, provided the original author and source are credited.

\section{Fissurectomy Versus Lateral Internal Sphincterotomy in the Treatment of Chronic Anal Fissure: A Randomized Control Trial}

Bipin Kishore Bara ${ }^{1}$, Sujit Kumar Mohanty ${ }^{2}$, Satya Narayan Behera ${ }^{2}$, Ashok Kumar Sahoo ${ }^{2,} 3$, Santanu Kumar Swain ${ }^{2}$

1. Surgery, Santha Bhima Bhoi Medical College and Hospital, Balangir, IND 2. Surgery, Srirama Chandra Bhanja Medical College and Hospital, Cuttack, IND 3. Surgery, Jawaharlal Institute of Postgraduate Medical Education \& Research, Puducherry, IND

Corresponding author: Ashok Kumar Sahoo, dr.ashoksahoo2010@gmail.com

\section{Abstract \\ Introduction}

An anal fissure is defined as a longitudinal split in the distal anoderm which extends from the anal verge to the dentate line. Fissures can be of primary or secondary type. The posterior midline is the most common location for primary fissures, while, anterior primary fissures, though rare, are more common in females. The cause of primary fissure is idiopathic. But secondary fissures are associated with other systemic diseases and can occur at an abnormal position anywhere in the anoderm. A high percentage of acute fissures heal spontaneously within three weeks with conservative medical management comprising of a high fiber diet, warm sitz bath, and topical analgesic with steroids. Secondary anal fissures will not heal in any form of treatment until the primary cause is addressed. These fissures often need surgical treatment. The lateral internal sphincterotomy (LIS) is one of the most practiced treatments for chronic anal fissure. Nonetheless, anal incontinence is one of the worrisome complications of LIS. Fissurectomy is one of the options among those techniques which address the issues with LIS. Some studies showed that patients with chronic fissures who are refractory to medical treatment responded well to fissurectomy. Hence, this study was conducted to compare the outcomes of fissurectomy and lateral internal sphincterotomy in the treatment of chronic anal fissure and compare recurrence and postoperative complications among both the procedures.

\section{Methods}

All consecutive patients attending the department of surgery with chronic fissure and age above 18 years were included in the study. All the included patients were randomized into two groups (fissurectomy and LIS) using the serially numbered opaque-sealed envelope (SNOSE) technique. The patients were discharged on the third day. The first visit was scheduled after two weeks and subsequent visits on the first and second months. Then the patients were followed up by telephonic conversation for the next six months. At the end of the follow-up, post-surgical complications were enquired, recorded, and interpreted.

\section{Results}

In the present study, out of a total of 87 patients, 80 patients were included in the study. Among all the patients, 16 patients (20\%) developed retention of urine. Four patients in the LIS group showed retention of urine whereas in the fissurectomy group it was twelve. The difference was not statistically significant (pvalue: 0.025$)$. A total of 10 patients required catheterization postoperatively. More patients in the fissurectomy group developed incontinence to flatus (p-value: 0.02 ). Incontinence to liquid and solid was significantly higher in the fissurectomy group (p-value: 0.03 and 0.002 , respectively).

\section{Conclusion}

In the present study, it was found that LIS was a better treatment option for chronic anal fissure than Fissurectomy. The postoperative complications were less in LIS than in fissurectomy. But the recurrence was higher in the LIS group while there was no recurrence in the fissurectomy group.

Categories: Gastroenterology, General Surgery

Keywords: catheterisation, sitz bath, incontinence, high fibre diet, fissures

\section{Introduction}

An anal fissure is a common benign anorectal problem resulting in pain and bleeding during defecation. An anal fissure is defined as a longitudinal split in the distal anoderm which extends from the anal verge to the dentate line [1]. The pain is excruciating, persists for few hours after defecation, and is quite disturbing in day-to-day life. The bleeding occurs as a streak of blood in the stool or sometimes it stains the toilet paper. Fissures can be of primary or secondary type. According to Pelta, primary fissures occur most commonly in 
the posterior midline ( $90 \%$ ) but about $10 \%$ can occur in the anterior position, which is more common in females [2]. A study done by Boulos revealed the incidence of the posterior and anterior fissures was $85.7 \%$ and $14.2 \%$, respectively [3]. The cause of primary fissure is idiopathic. A few studies hypothesized that a relatively ischemic environment formed by a decrease in blood flow to the midline portion of the anus with associated sphincter spasm may be the reason for these anal fissures $[4,5]$. The additional stretching of the anal canal causing worsening of the tear is usually prevented by the existing natural anal spasm. A vicious cycle sets in comprising of the anal spasm which exacerbates the ischemia and prevents the healing of the fissure. This, in turn, prevents the further tearing of fissures by sustaining the anal spam. And once the cycle commences, the chance of spontaneous healing of the fissure goes down and the edges of the fissure get more fibrosed, giving rise to a chronic fissure [6]. But secondary fissures are associated with other systemic diseases (like HIV infection, Crohn's disease, Tuberculosis, diabetes, immunosuppression, anorectal malignancy, etc.) and can occur at an abnormal position anywhere in the anoderm. A high percentage of acute fissures heal spontaneously within three weeks with conservative medical management comprising of a high fiber diet, warm sitz bath, and topical analgesic with steroid [7]. But the same treatment is not fruitful for treating a chronic anal fissure. Secondary anal fissures will not heal in any form of treatment until the primary cause is addressed. Chronic anal fissure overlies the fibers of the internal anal sphincter with a sentinel skin tag externally and internally it extends up to a hypertrophied papilla. These fissures often need surgical treatment. Basing on the principle of lowering the internal anal sphincter tone and avoiding the risk of fecal incontinence, various surgical treatment modalities have been developed in the last two decades. The lateral internal sphincterotomy is one of the most practiced treatments for chronic anal fissure. Nonetheless, it is having its complications like anal incontinence in approximately $30 \%$ of the cases [8]. Therefore, a lot of other techniques have been proposed for chronic anal fissure. Fissurectomy is one of the options among those techniques to treat chronic anal fissures. Many surgeons used this technique in patients with a high risk of incontinence, such as old age people, multiparous women, patients with the normal anal tone, and patients with a previous history of anorectal surgery [9]. Some studies showed that patients with chronic fissures who are refractory to medical treatment responded well to fissurectomy [10]. Hence, this study was conducted to compare the outcomes of fissurectomy and lateral internal sphincterotomy (LIS) in the treatment of chronic anal fissure and compare recurrence and postoperative complications among both the procedures.

\section{Materials And Methods}

The study was conducted in the department of general surgery at a tertiary care hospital in Eastern India from February 2019 to January 2021. The study was approved by the ethics committee of the institute and has been performed in accordance with the ethical standards laid down in an appropriate version of the Declaration of Helsinki (as revised in Brazil 2013).

All consecutive patients attending the department of surgery with chronic anal fissure and age above 18 years were included in the study. The details of the patients and the findings were recorded. Patients with multiple anal fissures, recurrent fissures, fissures with hemorrhoids and fistula, fissures associated with malignancies, fissures secondary to specific diseases like tuberculosis, etc., pregnant women were excluded from the study.

The study was designed as a prospective, open-labeled, parallel-arm, randomized controlled trial (RCT). Block randomization was carried out using a computer program with randomly selected block sizes of four and six. Allocation concealment was ensured by a serially numbered opaque-sealed envelope (SNOSE).

All consecutive patients with chronic anal fissure were recruited in the primary cohort, after obtaining written informed consent. All of them were initially managed according to the same conservative standard protocol, namely, medical treatment including dietary modification, stool softeners, and local ointments. All patients were assessed five to six weeks after the first visit, and surgical treatment was offered in the case of refractory symptoms. All the included patients were randomized into two groups (fissurectomy and LIS) using the SNOSE technique. The patients were started on stool softener two days before surgery. They were kept on a liquid diet 24 hours before the operation. On the day of operation, the patients were given an enema to avoid any soiling during surgery. All the patients underwent surgery in the lithotomy position after giving spinal anesthesia. Prophylactic parenteral antibiotics were administered just before the procedure according to a standardized protocol.

In the fissurectomy group, anal dilatation was done for four minutes by using a four-finger technique followed by fissurectomy. The fissure was excised using a scalpel, and the wound was curated till a healthy margin was reached up to the level of the internal sphincter. Thus a fresh ulcer was made without scar tissue and was allowed to heal by secondary intention. The presence of any concomitant skin tag or sentinel pile was also excised.

In the LIS group, the surgery was done using the closed method. A bivalve speculum was inserted into the anal canal. The groove between the internal and external anal sphincter was felt with the left-hand index finger. Then a scalpel was inserted into the groove and cautiously turned towards the internal sphincter to divide the muscle partially at the level of the apex of the fissure. 


\section{Cureus}

Hemostasis was achieved in both procedures.

Then an anal pack was given to stop any minor bleeding which was taken out after 24 hours and an oral liquid diet was started after four hours. All the patients were kept on IV antibiotics and analgesics for an appropriate period. The patients were discharged on the third day after a final look into the wound.

They were advised to do a warm sitz bath and use a stool softener for two to three weeks along with local ointment to lubricate the anal canal. The first visit was scheduled after two weeks and subsequent visits on the first and second months. Then the patients were followed up by telephonic conversation for the next six months. At the end of the follow-up, post-surgical complications were enquired, recorded, and interpreted.

\section{Statistical analysis}

Data were analyzed by using SPSS Statistics for Windows, Version 20.0 (IBM SPSS Statistics for Windows, Version 20.0. Armonk, NY: IBM Corp). Appropriate statistical tests were used to compare the results of fissurectomy and LIS. Descriptive results were expressed as mean and SD of various parameters. $p<0.05$ was considered statistically significant.

\section{Results}

In the present study, out of a total of 87 patients, 80 patients were included in the study (Figure 1 ).

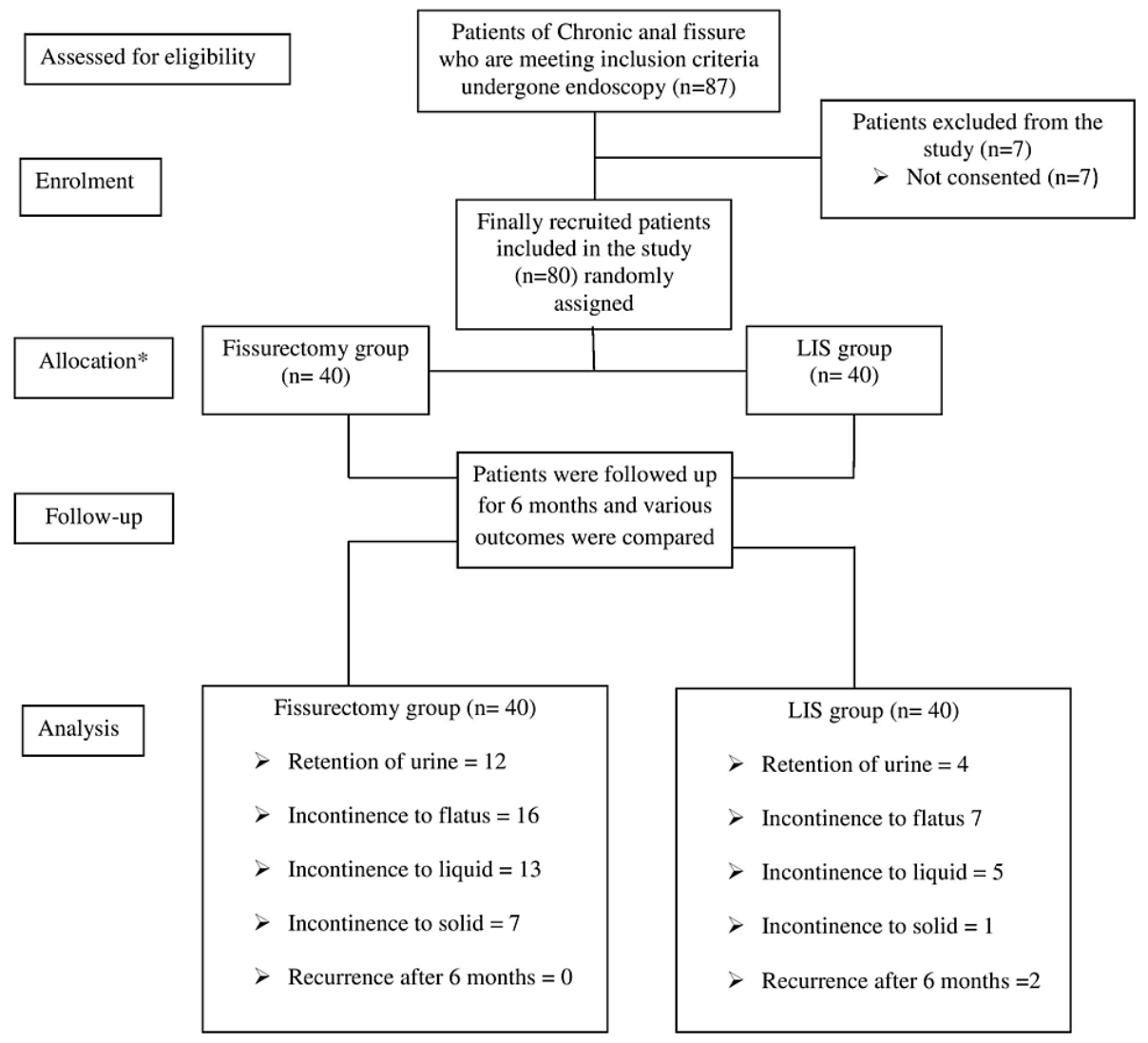

LIS- Lateral Internal Sphincterotomy

*Allocation concealment was done by opaque sealed envelope method

FIGURE 1: The overall scheme as per CONSORT flowchart.

CONSORT: CONsolidated Standards Of Reporting Trials.

All the seven patients who were excluded from the study had not given consent for the same.

The mean age in fissurectomy and LIS groups was $37.23 \pm 11.231$ and $39.342 \pm 10.246$ years, respectively.

There were 19 males (47.5\%) and 21 females (52.5\%) in the fissurectomy arm while the LIS arm comprised 


\section{Cureus}

18 males (45\%) and 22 females (55\%). The gender distribution between the groups was also comparable and the male-to-female ratio in both the groups did not vary significantly $(48 / 52 \%$ vs. $45 / 55 \%$; $\mathrm{p}=0.714)$. After surgery, almost all patients got relief from pain and bleeding within one week period.

The postoperative complications were depicted in Table 1 and Table 2 for the fissurectomy group and LIS group, respectively.

\begin{tabular}{|c|c|c|c|c|}
\hline & Complications & Male $(n=20)$ & Female $(n=20)$ & Total $(n=40)$ \\
\hline 1 & Retention of urine & 7 & 5 & 12 \\
\hline 2 & Incontinence to flatus & 6 & 10 & 16 \\
\hline 3 & Incontinence to liquid & 4 & 9 & 13 \\
\hline 4 & Incontinence to solid & 2 & 5 & 7 \\
\hline 5 & Recurrence after 6 months & 0 & 0 & 0 \\
\hline
\end{tabular}

TABLE 1: Complications in fissurectomy group.

\begin{tabular}{|c|c|c|c|c|}
\hline & Complications & Male $(n=20)$ & Female $(n=20)$ & Total $(n=40)$ \\
\hline 1 & Retention of urine & 2 & 2 & 4 \\
\hline 2 & Incontinence to flatus & 1 & 6 & 7 \\
\hline 3 & Incontinence to liquid & 1 & 4 & 5 \\
\hline 4 & Incontinence to solid & 0 & 1 & 1 \\
\hline 5 & Recurrence after 6 months & 2 & 0 & 2 \\
\hline
\end{tabular}

TABLE 2: Complications in lateral internal sphincterotomy (LIS) group.

In the fissurectomy group, 12 patients (30\%) developed retention of urine, of whom seven were male and the rest were female. A total of 16 patients (40\%) showed incontinence to flatus which was found to be more in females (six males and 10 females). Thirteen patients became incontinent to liquid (32.5\%), most of whom were female. Incontinence to solid was seen in seven patients (17.5\%), with five of them being female. There was no recurrence in this group after six months of follow-up.

In the LIS group, four patients (10\%) developed retention of urine, two each male and female. A total of seven patients (17.5\%) showed incontinence to flatus which was found to be more in females (one male and six females). Five patients became incontinent to liquid (12.5\%), most of whom were female. Incontinence to solid was seen in one patient (2.5\%), who was a female. A total of two male patients $(5 \%)$ had recurrence after six months.

Table 3 illustrated the comparison of postoperative complications among both groups. 


\section{Cureus}

\begin{tabular}{|c|c|c|c|c|}
\hline & Complications & Fissurectomy group & LIS group & p-value \\
\hline 1 & Retention of urıne & 12 & 4 & 0.025 \\
\hline 2 & Incontinence to flatus & 16 & 7 & 0.02 \\
\hline 3 & Incontinence to liquid & 13 & 5 & 0.03 \\
\hline 4 & Incontinence to solid & 7 & 1 & 0.02 \\
\hline
\end{tabular}

TABLE 3: Comparison of complications between fissurectomy and lateral internal sphincterotomy (LIS) group.

Among all the patients, 16 patients (20\%) developed retention of urine. Four patients in the LIS group showed retention of urine whereas in the fissurectomy group it was 12 . The difference was not statistically significant (p-value: 0.025 ). A total of 10 patients required catheterization postoperatively. More patients in the fissurectomy group developed incontinence to flatus ( $\mathrm{p}$-value: 0.02). Incontinence to liquid and solid was significantly higher in the fissurectomy group (p-value: 0.03 and 0.002 , respectively).

None of the patients developed key-hole deformity in both groups.

\section{Discussion}

Sphincterotomy as the surgical treatment of choice for chronic anal fissure was first described by Boyer [11]. Following that, a lot of procedures have been developed to address the issue. Fissurectomy, anal dilatation, posterior and lateral sphincterotomy, and advancement flap are few proposed procedures among them [12]. In lateral internal sphincterotomy, the internal sphincter is divided in its distal third away from the fissure itself - either in the right or left lateral position [13]. The main aim of LIS is to increase the blood flow of the anoderm by decreasing the maximum anal sphincter pressure by $18 \%-50 \%$. The rate of healing of fissure was ranging from $93 \%$ to $95 \%$ in the open technique which scores to $90 \%$ to $97 \%$ by using the close technique. In the present study, the close technique was carried out. Still, fissurectomy with manual dilatation is advocated in young adults with very high sphincter tone. In France, the procedure of choice for chronic anal fissure, refractory to medical management, is fissurectomy. This is based on the anecdotal and published evidence that fissurectomy exhibits a comparable rate of healing as compared to LIS. A German study demonstrated favorable results with fissurectomy as the procedure of choice for chronic anal fissure [14]. In the present study, after surgery, almost all patients got relief from pain and bleeding within one week period.

Up to 35\% of patients developed complications following LIS in a study done by Khubchadani et al [15]. Another study conducted by Littlejohn et al documented 35\% of patients complained of minor straining following LIS [16]. The risk factors for continence disturbance include age over 40 years, female sex, history of vaginal delivery, anterior fissure, the addition of synchronous anorectal procedure, and technique [17]. Charua et al. found that $6.5 \%$ of patients following LIS developed minimal fecal incontinence at three months post-surgery [18]. As per the study done by Nyam et al., the patients developing incontinence to flatus, mild soiling, and gross incontinence were $31 \%, 39 \%$, and $23 \%$, respectively [19].

A study done by Hoffman and Goliger revealed that patients undergoing LIS had occasional incontinence to flatus and feces [20]. Garcia et al demonstrated that incontinence among patients undergoing LIS was raging from $16.1 \%$ to $26.7 \%$ [21].

But contrary to the above studies, Walker et al found different results in their study [22]. They conducted a long-term follow-up for 4.3 years in 100 patients who had undergone LIS and found a moderate degree of soiling ranging from $3 \%$ to $5 \%$. Mousavi reported no incidence of fecal soiling and incontinence to flatus [23]. No long-term complication was observed by Adriano Tocchi in his study on LIS [24].

Aziz in his study on 146 patients found a cure rate of $97.5 \%$ over three months period and there was no longterm complication and patient compliance was 100\% [25]. Flatus incontinence was found in $4.1 \%$ of patients but that was transitory. Schouten WR et al. in his study on LIS found pain relief in 98\% of cases [26]. Daniel $\mathrm{O}$ in his study of chronic anal fissures found that LIS is an effective procedure with a high rate of resolution of symptoms but with a risk of temporary or permanent incontinence [27].

In the present study, four patients in the LIS group showed retention of urine whereas in the fissurectomy group it was twelve. Among them, 10 patients required catheterization postoperatively. More patients in the fissurectomy group developed incontinence to flatus (p-value: 0.02). Incontinence to liquid and solid was significantly higher in the fissurectomy group (p-value: 0.03 and 0.002, respectively). No recurrence was found in the fissurectomy group. Unfortunately, two male patients developed recurrence after undergoing 
As the anal canal is shorter in females, the risk of sphincter injury is more during delivery [28]. According to several studies, the LIS procedure becomes more extensive in females than in males [29,30]. This may be one of the reasons for getting more complications in female patients in the present study.

Keyhole deformity is one of the worst complications of fissurectomy which may lead to fecal soiling. Fortunately, in the present study, none of the patients developed such complications.

There are few limitations in the present study. The sample size of the study was less. It was a single-center study.

\section{Conclusions}

In the present study, it was found that LIS was a better treatment option for chronic anal fissure than fissurectomy. The postoperative complications were less in LIS than in fissurectomy. But the recurrence was higher in the LIS group while there was no recurrence in the fissurectomy group. Four finger dilatation followed by fissurectomy is a better option for young male patients whose resting anal sphincter pressure is high, and also in females with previous obstetric trauma, and short anal canal. As the sample size is small, further studies are needed to establish the conclusion.

\section{Additional Information \\ Disclosures}

Human subjects: Consent was obtained or waived by all participants in this study. Institute Ethics Committee (Human Studies) issued approval 11/IEC,BBMCH, BALANGIR, DT. 05.02.2019. A Randomized Control Trial (RCT) was conducted in Santha Bhima Bhoi Medical College \& Hospital, Balangir, Odisha. The ethical committee passed the study vide project no 11/IEC, BBMCH, BALANGIR, DT.05.02.2019. Animal subjects: All authors have confirmed that this study did not involve animal subjects or tissue. Conflicts of interest: In compliance with the ICMJE uniform disclosure form, all authors declare the following: Payment/services info: All authors have declared that no financial support was received from any organization for the submitted work. Financial relationships: All authors have declared that they have no financial relationships at present or within the previous three years with any organizations that might have an interest in the submitted work. Other relationships: All authors have declared that there are no other relationships or activities that could appear to have influenced the submitted work.

\section{References}

1. Dziki A, Trzcinski R, Langner E, Wronski W: New approaches to the treatment of anal fissure . Acta Chir Iugosl. 2002, 49:73-5. 10.2298/aci0202073d

2. Pelta AE, Davis KG, Armstrong DN: Subcutaneous fissurotomy: a novel procedure for chronic fissure-inano. a review of 109 cases. Dis Colon Rectum. 2007, 50:1662-7. 10.1007/s10350-007-9022-5

3. Boulos PB, Araujo JG: Adequate internal sphincterotomy for chronic anal fissure: subcutaneous or open technique?. Br J Surg. 1984, 71:360-2. 10.1002/bjs.1800710517

4. De Nardi P, Ortolano E, Radaelli G, Staudacher C: Comparison of glycerine trinitrate and botulinum toxin-a for the treatment of chronic anal fissure: long-term results. Dis Colon Rectum. 2006, 49:427-32. 10.1007/s10350-005-0287-2

5. Jonas M, Speake W, Scholefield JH: Diltiazem heals glyceryl trinitrate-resistant chronic anal fissures: a prospective study. Dis Colon Rectum. 2002, 45:1091-5. 10.1007/s10350-004-6365-z

6. Villalba H, Villalba S, Abbas MA: Anal fissure: a common cause of anal pain . Perm J. 2007, 11:62-5. 10.7812/tpp/07-072

7. Beaty IS, Shashidharan M: Anal Fissure. Clin Colon Rectal Surg. 2016, 29:30-7. 10.1055/s-0035-1570390

8. Garg P, Garg M, Menon GR: Long-term continence disturbance after lateral internal sphincterotomy for chronic anal fissure: a systematic review and meta-analysis. Colorectal Dis. 2013, 15:e104-17. 10.1111/codi.12108

9. Zeitoun JD, Blanchard P, Fathallah N, Benfredj P, Lemarchand N, de Parades V: Long-term outcome of a fissurectomy: a prospective single-arm study of 50 operations out of 349 initial patients. Ann Coloproctol. 2018, 34:83-7. 10.3393/ac.2017.06.12

10. Schornagel IL, Witvliet M, Engel AF: Five-year results of fissurectomy for chronic anal fissure: low recurrence rate and minimal effect on continence. Colorectal Dis. 2012, 14:997-1000. 10.1111/j.14631318.2011.02840.x

11. McNamara MJ, Percy JP, Fielding IR: A manometric study of anal fissure treated by subcutaneous lateral internal sphincterotomy. Ann Surg. 1990, 211:235-8. 10.1097/00000658-199002000-00017

12. Nelson RL: Meta-analysis of operative techniques for fissure-in-ano. Dis Colon Rectum. 1999, 42:1424-8. 10.1007/BF02235041

13. Notaras MJ: Lateral subcutaneous sphincterotomy for anal fissure--a new technique. Proc R Soc Med. 1969, 62:713.

14. Meier zu Eissen J: Chronic anal fissure, therapy . Kongressbd Dtsch Ges Chir Kongr. 2001, 118:654-6. 10.1007/978-3-642-56458-1 231

15. Khubchandani IT, Reed JF: Sequelae of internal sphincterotomy for chronic fissure in ano . Br J Surg. 1989, 76:431-4. 10.1002/bjs.1800760504 
16. Littlejohn DR, Newstead GL: Tailored lateral sphincterotomy for anal fissure . Dis Colon Rectum. 1997, 40:1439-42. 10.1007/BF02070709

17. Meyer I, Richter HE: Impact of fecal incontinence and its treatment on quality of life in women . Womens Health. 2015, 11:225-38. 10.2217/whe.14.66

18. Charúa GL, Sánchez MJ, Avendaño EO: Fecal incontinence secondary to partial internal lateral sphincterotomy as part of the surgical treatment of chronic anal fissure. Cir Gen. 2006, 28:170-6.

19. Nyam DC, Pemberton JH: Long-term results of lateral internal sphincterotomy for chronic anal fissure with particular reference to incidence of fecal incontinence. Dis Colon Rectum. 1999, 42:1306-10. 10.1007/BF02234220

20. Hoffmann DC, Goligher JC: Lateral subcutaneous internal sphincterotomy in treatment of anal fissure $\mathrm{Br}$ Med J. 1970, 3:673-5. 10.1136/bmj.3.5724.673

21. Garcia-Aguilar J, Belmonte C, Wong WD, Lowry AC, Madoff RD: Open vs. closed sphincterotomy for chronic anal fissure: long-term results. Dis Colon Rectum. 1996, 39:440-3. 10.1007/BF02054061

22. Walker WA, Rothenberger DA, Goldberg SM: Morbidity of internal sphincterotomy for anal fissure and stenosis. Dis Colon Rectum. 1985, 28:832-5. 10.1007/BF02555487

23. Mousavi SR, Sharifi M, Mehdikhah Z: A comparison between the results of fissurectomy and lateral internal sphincterotomy in the surgical management of chronic anal fissure. J Gastrointest Surg. 2009, 13:1279-82. 10.1007/s11605-009-0908-5

24. Tocchi A, Mazzoni G, Miccini M, Cassini D, Bettelli E, Brozzetti S: Total lateral sphincterotomy for anal fissure. Int J Colorectal Dis. 2004, 19:245-9. 10.1007/s00384-003-0525-9

25. Aziz A, Sheikh I: Lateral subcutaneous internal sphincterotomy in chronic anal fissure . Pakistan J Surg. 2009, 26:93-6.

26. Schouten WR, Briel JW, Auwerda JJ, De Graaf EJ: Ischaemic nature of anal fissure. Br J Surg. 1996, 83:63-5. 10.1002/bjs.1800830120

27. Herzig DO, Lu KC: Anal fissure. Surg Clin North Am. 2010, 90:33-44. 10.1016/j.suc.2009.09.002

28. Kement M, Karabulut M, Gezen FC, Demirbas S, Vural S, Oncel M: Mild and severe anal incontinence after lateral internal sphincterotomy: risk factors, postoperative anatomical findings and quality of life. Eur Surg Res. 2011, 47:26-31. 10.1159/000324902

29. Casillas S, Hull TL, Zutshi M, Trzcinski R, Bast JF, Xu M: Incontinence after a lateral internal sphincterotomy: are we underestimating it?. Dis Colon Rectum. 2005, 48:1193-9. 10.1007/s10350-004-09143

30. Damon H, Bretones S, Henry L, Mellier G, Mion F: Long-term consequences of first vaginal delivery-induced anal sphincter defect. Dis Colon Rectum. 2005, 48:1772-6. 10.1007/s10350-005-0075-Z 